\title{
FLORAL ANALYSIS: FRESH AND DRY WEIGHT OF FLOWERS FROM DIFFERENT FRUIT TREE SPECIES.
}

\author{
L. Montañés Millán ${ }^{1}$, J. Val ${ }^{1}$, J. Betrán ${ }^{2}$, E. Monge ${ }^{1}$, M.A. Moreno ${ }^{1}$ and L. \\ Montañés ${ }^{1}$. \\ ${ }^{1}$ Estación Experimental de Aula Dei (CSIC), Apdo. 202, 50080, Zaragoza, \\ SPAIN.
}

2 Laboratorio Agroambiental (DGA), Apdo. 727, 50080, Zaragoza

SPAIN.

\begin{abstract}
$\underline{\text { Abstract }}$
Floral analysis could be considered as an alternative versus foliar analysis to diagnose the nutritional status of fruit trees. Taken into account the importance of the dry matter percentage of any plant tissue, preliminary results about fresh and dry weights of flowers from different fruit species are presented in this study. For this purpose, whole flowers (without stalk) at full bloom were sampled from different fruit species grown at the Aula Dei Campus. The fruit tree groups considered for these studies were: almond, apple, apricot, nectarine, peach, pear, plum, sour cherry and sweet cherry. For the last group, three varieties: (Sunburst, Tardif de Vignole and Van) were studied. Significant differences, among groups, for fresh weights, dry weights and dry matter percentages were found.
\end{abstract}

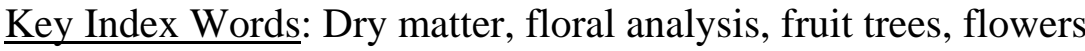

\section{Introduction}

Plant material analysis as a nutritional diagnosis tool has contributed for many years to the improvement of fruit crop productivity (yield and quality) reducing at the same time the environmental or health risks that might result from an advanced agriculture. A number of philosophies and methods of nutrient diagnosis have been used since plant tissue analysis began, but each has its weakness and disadvantages (Beverly, 1991).

Foliar analysis can be a useful tool for assessing plant nutrient status, only when adequate procedures are available, for making diagnosis from analytical data based on reference values. Foliar diagnosis could be too complex or too late to be effective because foliar composition is dynamically influenced by ageing processes as well as by interactions (soil and plant dependent) affecting nutrient uptake and distribution. (Walworth and Summer, 1987).

Flowers are organs of such short life that are less time exposed than leaves to metabolic changes and management practices. Therefore, floral analysis could permit an early diagnosis or to prognose an abnormal nutritive situation, before symptoms are perceivable. This ability of floral analysis could be of remarkable interest if applied to early ripening cultivars. Recent publications from Sanz et al. $(1994,1995)$ and Sanz and Montañés (1995), have introduced these possibilities. 
A hypothetical use of floral analysis for fruit tree species, once standarized the corresponding methodology to diagnose plant nutritional status, might allow agronomists and growers to have the following advantages:

- A narrower sampling time, then a smaller risk of errors due to ageing.

- Plant material, eventually, with a less risk to be contaminated by chemicals, pests or diseases.

- Sampling time is a function of the particular phoenological development (flowering stage) of each variety or combination rootstock-scion.

- Materials can be easily manipulated in the laboratory (cleaning, drying and milling).

On the other hand, the nutrient concentration in plant material, whatever it can be, as expressed on a dry matter basis, is a function of the speed rate of nutrient uptake and dry mass accumulation. Heras et al (1971) found that the apparent image of a particular nutritional situation could be very different depending on the base chosen to express the analytical data (fresh or dry matter). An example of the dry matter importance into the nutritional concepts is the remarkable expansion of the modified DRIS (M-DRIS) interpretative approach proposed by Walworth et al. (1986) and Hallmark et al. (1987), including nutrient ratios with dry matter. In this case, dry matter is treated as an additional plant constituent, which is essentially the sum of three nutrients usually ignored in nutritional considerations $(\mathrm{C}, \mathrm{H}$ and $\mathrm{O})$. In fact, the dry matter index of a plant should be representative of the processes of $\mathrm{C}, \mathrm{H}$ and $\mathrm{O}$ acquisition (Walworth and Sumner, 1987).

Summarizing, three aspects may be taken into account concerning the importance of the study of plant dry matter:

- First, quantitative, considering dry matter as an analytical parameter as well as a basis to refer mineral nutrient concentrations (\%, ppm, etc.).

- Second, as a parameter for the qualitative evaluation of yield or final product (Guldan and Martin, 1996), and to define the kind and dynamics of growth (Giovannini et al., 1994).

- Finally, it exists a practical aspect referred to the minimum quantity of dry matter (sample) necessary to carry out the analytical procedures.

The objective of this work was to know the fresh and dry mass of flowers from eight fruit tree species. These data will be useful as a previous step to standarize the application of floral analysis.

\section{Material and Methods}

Whole flowers (without stalk) were sampled at full bloom during the winterspring of 1996 from fruit orchards of the Estación Experimental de Aula Dei and Servicio de Investigación Agroambiental, farms, Zaragoza, NE Spain. The best practical procedure for sampling flowers consists on cutting (avoiding pulling them up) at the level of the stalk by making pressure with the forefinger nail over the thumb. Care has to be taken to collect complete flowers (if they are too mature, petals could fall). The 
best time for sampling during the flowering stage is when the trees have $80-90 \%$ of their flowers completely opened.

For this study, the following fruit tree groups (species or varieties) were considered:

- Almond: (Prunus dulcis, Mill.). Sampling date: 29-2-96.

- Apple: (Malus pumila, Mill). Sampling date: 16-4-96

- Apricot (Prunus armeniaca, L.). Sampling dates: 13 and 19-3-96.

- Nectarine (Prunus persica, L. Batsch). Sampling date 19-3-96.

- Peach (Prunus persica, L. Batsch). Sampling date: 25-3-96.

- Pear (Pyrus communis L.). Sampling date 28-3-96.

- Plum (Prunus domestica, L.). Sampling date 28-3-96.

- Sour cherry (Prunus. ceraesus, L.). Sampling date 16-4-96.

- Sweet cherries (Prunus avium, L.) Three cultivars were included: Sumburst, Tardif de Vignole and Van. Sampling dates: 19-4-96, 17-4-96, 3-4-96 respectively.

Excellent descriptions of these flowers can be found in Westwood (1993).

Ten trees per each of the nine groups considered were sampled irrespective of rootstock and variety, except for sweet cherry (30 trees because 3 varieties have been included). Fifty flowers per tree were collected from the central part of the shoots around the canopy.

Sampled material was immediately weighted, and dried in an air forced stove for $48 \mathrm{~h}$ at $60^{\circ} \mathrm{C}$. Dry matter percentage (DM) was calculated from fresh (FW) and dry (DW) weights. The data were evaluated by analysis of variance and means were separated by Duncan's test when the F test was significant.

Table 1. Fresh weight, dry weight, and dry matter percentage of 50 flowers from 9 fruit tree groups and 3 sweet cherry varieties.

Fresh weight (g)

Dry weight (g)

Dry matter percentage mean \pm sd maximum minimum mean \pm sd maximum minimum mean \pm sd maximum minimum

\begin{tabular}{l|ccccccccc}
\hline \multicolumn{2}{l}{ Fruit Tree Groups } & & & & & & & \\
Almond & $13.7 \pm 2.2$ & 17.1 & 10.7 & $2.5 \pm 0.4$ & 3.1 & 2.0 & $18.5 \pm 0.4$ & 19.2 & 18.0 \\
Apple & $14.1 \pm 1.8$ & 16.4 & 11.4 & $2.4 \pm 0.3$ & 2.9 & 1.9 & $17.4 \pm 0.3$ & 17.9 & 16.7 \\
Apricot & $10.1 \pm 0.7$ & 11.9 & 9.3 & $1.7 \pm 0.1$ & 1.9 & 1.5 & $16.6 \pm 1.0$ & 18.2 & 14.9 \\
Nectarine & $14.5 \pm 0.4$ & 15.1 & 13.8 & $2.6 \pm 0.1$ & 2.8 & 2.5 & $17.9 \pm 0.5$ & 18.7 & 17.3 \\
Peach & $12.7 \pm 0.8$ & 13.9 & 11.3 & $2.3 \pm 0.2$ & 2.9 & 2.1 & $18.5 \pm 2.5$ & 25.4 & 16.2 \\
Pear & $8.7 \pm 0.5$ & 9.8 & 7.9 & $1.6 \pm 0.1$ & 1.8 & 1.5 & $18.4 \pm 0.5$ & 19.2 & 17.2 \\
Plum & $5.7 \pm 0.3$ & 6.2 & 5.3 & $1.1 \pm 0.1$ & 1.2 & 1.0 & $19.1 \pm 1.0$ & 20.3 & 16.9 \\
Sour cherry & $5.6 \pm 0.5$ & 5.6 & 6.2 & $1.0 \pm 0.1$ & 1.1 & 0.8 & $16.9 \pm 0.5$ & 17.9 & 16.3 \\
Sweet cherry & $7.6 \pm 0.8$ & 8.9 & 5.3 & $1.3 \pm 0.2$ & 1.7 & 0.9 & $17.3 \pm 1.3$ & 19.2 & 15.5 \\
Sweet cherry varieties & & & & & & & & \\
Sumburst & $7.7 \pm 0.6$ & 8.9 & 8.6 & $1.4 \pm 0.08$ & 1.5 & 1.2 & $18.2 \pm 0.6$ & 19.0 & 17.1 \\
T. Vignole & $8.0 \pm 0.5$ & 8.9 & 7.3 & $1.4 \pm 0.13$ & 1.7 & 1.3 & $17.8 \pm 1.1$ & 19.2 & 15.9 \\
Van & $7.2 \pm 1.0$ & 8.7 & 5.3 & $1.1 \pm 0.14$ & 1.4 & 0.9 & $15.9 \pm 0.3$ & 16.6 & 15.5 \\
\hline
\end{tabular}

\section{Results and Discussion}

The objective of this work was not only to corroborate if differences between species or cultivars (in the cases of sweet cherry) occurred, but also to give a 
preliminary information about the values of fresh and dry mass of flowers from fruit tree species.

Table 1 shows the means of fresh weight, dry weight and dry matter percentage corresponding to the 9 fruit tree groups and three sweet cherry varieties.

The flowers from the nectarine fruit group showed the highest FW and DW values (14.5 and $2.6 \mathrm{~g}$ respectively), but the highest DM corresponded to those of plum tree (19.1\%). The minimum values were obtained from sour cherry (5.6 g and $1.0 \mathrm{~g}$ for FW and DW, respectively) and from apricot for DM (16.6\%).

Table 2. Fresh weight: significance (at the 0.050 level) of inter-groups differences for 50 flowers.

Sour cherry

Sour C Plum Swt. C. Pear Apric. Peach Almo. Apple

Plum

Sweet cherry

Pear

Apricot

Peach

Almond

Aple

Nectarine

* and NS denote differences statistically significant or not respectively.

In Tables 2, 3 and 4 appear represented the significance of the difference between pairs of groups for FW, DW and DM.

From Table 2, it can be deduced that among the 36 possible combinations (pairs of groups), only in four cases (plum-sour cherry, apple-almond; nectarine-almond; nectarine-apple) the differences in FW were not significant. Regarding DW (Table 3), the differences were significant neither for these four pairs nor for the apple-peach and apricot-pear. It is a prominent fact that for both FW and DW, exists significant differences between two groups of the same specie (peach and nectarine). This, would be a manifestation of the influence of the variety on the flower characteristics as an analytical material. In leaves, this influence is generally accepted for most tree fruit species.

Table 3. Dry weight: significance (at the 0.050 level) of inter-groups differences for 50 flowers.

Sour cherry

Sour C Plum Swt. C. Pear Apric. Peach Apple Almo.

Plum

Sweet cherry

Pear

Apricot

Peach

Apple

Almond

Nectarine

\begin{tabular}{|c|c|c|c|c|c|c|}
\hline NS & & & & & & \\
\hline$*$ & $*$ & & & & & \\
\hline * & * & * & & & & \\
\hline * & $*$ & * & NS & & & \\
\hline$*$ & * & * & $*$ & * & & \\
\hline * & * & * & $*$ & * & NS & \\
\hline$*$ & * & * & * & * & * & NS \\
\hline * & $*$ & * & $*$ & * & $*$ & NS \\
\hline
\end{tabular}

* and NS denote differences statistically significant or not respectively. 
Table 4. Dry matter percentage: significance (at the 0.050 level) of inter-groups differences for 50 flowers.

Apricot

Apric Sour C Swt. C. Apple Nectar. Pear Peach Almo.

Sour cherry

Sweet cherry

Apple

Nectarine

Pear

Peach

Almond

Plum

* and NS denote differences statistically significant or not respectively.

\begin{tabular}{|c|c|c|c|c|c|c|c|}
\hline NS & & & & & & & \\
\hline NS & NS & & & & & & \\
\hline NS & NS & NS & & & & & \\
\hline$*$ & NS & NS & NS & & & & \\
\hline * & $*$ & $*$ & NS & NS & & & \\
\hline$*$ & $*$ & $*$ & NS & NS & NS & & \\
\hline$*$ & $*$ & $*$ & $*$ & NS & NS & NS & \\
\hline * & * & * & $*$ & $*$ & NS & NS & NS \\
\hline
\end{tabular}

If we refer these two parameters (FW and DW) in dry matter percentage, it can be proven that the differences among the species were no longer so dramatic (Table 4). They were only significant among 16 pairs of values (less than $50 \%$ of the cases). apricot and plum were the groups with greatest difference.

The already mentioned differences among groups in fresh and dry matter, can be specially important when interpreting the analytic results, in particular, when attempting to evaluate, through the analysis of flowers, the uptake of nutrients (requirements) by the plant.

To evaluate these results, it should be also kept in mind that the orchards, in which flowers were sampled, were in the same area, therefore subjected to similar management and soil conditions. Therefore, the observed differences might also be due to other factors as the climatic conditions before sampling. In this way, thinking about a future application of floral analysis, it is convenient to highlight that some of these factors (frost, winds, etc..) can dramatically affect the 'quality' of flowers.

Lastly, it is worthwhile to make a practical consideration. Assuming the use of analytical procedures for small samples (Ansorena et al 1995), it could be convenient to have in the laboratory, at least, $5 \mathrm{~g}$ of dry matter per sample. According to our results, to get these $5 \mathrm{~g}$, we can distribute the studied species in 3 categories: a) Those that will need between 200 and 250 flowers (plum, sweet and sour cherries); b) those of around 150 flowers (apricot and pear); and c) those of 100-110 flowers (almond, apple, nectarine and peach).

Among woody crops, in our growing conditions (Mediterranean area), cherry species are some of the earliest harvested in the season. For this reason, the early diagnosis of their nutritional status appears to be of major interest. Then, the application of floral analysis would be particularly important for these crops.

Table 5. Fresh weight, dry weight and dry matter percentage: significance (at the 0.050 level, among three sweet cherry varieties differences for 50 flowers

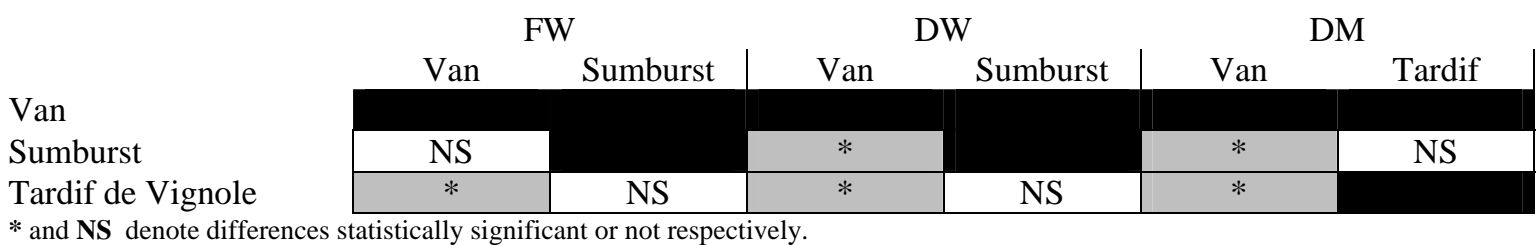


Regarding the particular case of sweet cherry trees, it is a remarkable fact that 'Tadif de Vignole' was the cultivar providing flowers with the greatest mass (8.0 g FW and $1.4 \mathrm{~g} \mathrm{DW}$ ), although the DM was lightly higher in 'Sumburst' (18.2\%). In contrast, the smallest values in FW, DW and DM (7.2 g, $1.1 \mathrm{~g}$ and 15.9\%, respectively) were obtained from 'Van' (Table 1).

Table 5 indicates that into the same specie (sweet cherry) they are significant differences among the cultivars for all parameters. This lead to the thinking that floral mass would also be of some value to differentiate sweet cherry varieties, in agreement, with the already highlighted for peach and nectarine. However, the practical applications of this approach (floral analysis) remain to be tested in a broader range of field situations

\section{4. $\quad$ Conclusions}

Significant differences for fresh weight, dry weight and dry matter percentage of flowers sampled from the studied fruit tree species and varieties were found. The means obtained for 50 flowers, ranged from 5.6 (Sour cherry) to $14.5 \mathrm{~g}$ (Nectarine) for FW, from 1.0 (Sour cherry) to $2.6 \mathrm{~g}$ (Nectarine) for DW and 16.6 (Apricot) to $19.1 \%$ (Plum) for DM.

These differences must be taken into account to standardise the flower sampling procedure, as different number of flowers was necessary to achieve an equivalent dry matter quantity.

\section{Acknowledgements}

This work was supported by research grants PCA-4/91 and PCA-6/91 CONAI (Diputación General de Aragón), and Comisión Interministerial de Ciencia y Tecnología projects AGR 91-0434 and AGF94-1030-003-01.

\section{References}

Ansorena, J., Echarri, R. And Hernani, J. 1995. Nota sobre determinación de N, P, Ca, Mg, y K, tras la digestión simultánea, en pequeñas cantidades de muestra de origen vegetal y animal. Invest. Agr.: Prod. Prot, veg. Vol. 10: 301-309.

Beverly, R. B. 1991. A practical guide to the diagnosis and recommendation integrated system (DRIS). Micro-Macro Publishing. Athens (Georgia). USA.

Giovannini, D. Glenn, D.M., Scorza, R. And Welker, W.V. Dry matter distribution of three peach growth types. HortScience 29: 1481-1483.

Guldan, S.J. and Martin, C.A. 1996. Dry-matter and nitrogen yields of legumes interseeded into sweet corn. HortScience, 31: 206-208.

Hallmark, W. B.; Walworth, J. L.; Sumner M. E.; De Mooy, J.; Pesek, J. and Shao, K. P. 1987. Separating limiting from non-limiting nutrients. J. Plant Nutr. 10 (916): 1381-1390.

Heras, L., Montañés, L. and Abadía, A. 1971. Importancia del contenido de agua en la interpretatición de los resultados en el fenómeno de clorosisi de hierro. An. Aula Dei. 11: 47-50. 
Sanz, M.; Carrera, M. and Montañes, L. 1994. The possibility of using floral analysis to diagnose the nutritional status of pear trees. Acta Horticulturae 367: 290-295.

Sanz, M., Val, J., Monge, E. and Montañes, L. 1995. Is it possible to diagnose the nutritional status of peach trees by chemical analysis of their flowers?. Acta Horticulturae 383: 159-163. (Revised paper).

Sanz, M., Montañes, L. 1995. Floral analysis: A novel approach for the prognosis of iron deficiency in pear (Pyrus communis, L.) and peach (Prunus persica L., Batsch). In: J. Abadía (ed.) Iron nutrition in soils and plants: 371-374. Kluwer Academic Publishers. The Netherlands.

Walworth, J. L. and Sumner, M. E. (1987). The diagnosis and recommendation integrated system (DRIS), pp. 149-188. In: B. A. Stewart (ed.), Advances of Soil Science, Vol. 6. Springer-Verlag. New York. USA.

Walworth, J. L., Letzsch, W. S. and Sumner M. E. 1986. Use of boundary lines in establishing diagnostic norms. Soil Sci. Soc. Am. J. 50: 123-128.

Wetswood, M. N. 1993. Temperate-zone pomology. Physiology and culture. Timber, Press. Portland. Oregon. USA 